Published in final edited form as:

Consult Pharm. 2014 December ; 29(12): 823-837. doi:10.4140/TCP.n.2014.823.

\title{
Mirabegron: A Beta-3 Agonist for Overactive Bladder
}

Rebecca Bragg, Pharm.D., BCPS,

PGY2 Ambulatory Care Resident, St. Louis College of Pharmacy/Department of Health

Danielle Hebel, Pharm.D., BCPS,

PGY2 Ambulatory Care Resident, St. Louis College of Pharmacy/St. Mary's Health Center

Scott Martin Vouri, Pharm.D., BCPS, CGP, and

Assistant Professor of Pharmacy Practice, St. Louis College of Pharmacy

Jamie M. Pitlick, Pharm.D., BCPS

Assistant Professor of Pharmacy Practice, St. Louis College of Pharmacy, 4588 Parkview Place, St. Louis, MO 63110, Tel: 314-768-8339, Fax: 314-446-8500

Jamie M. Pitlick: Jamie.pitlick@stlcop.edu

\section{Abstract}

Objective-To review the literature regarding the efficacy and safety of mirabegron for the treatment of overactive bladder $(\mathrm{OAB})$.

Data Sources-A literature search was performed using MEDLINE (PubMed) prior to 12/31/2013 using the terms "mirabegron" and "randomized-controlled trial."

Study Selection/Data Extraction-All published, double-blind, randomized controlled trials assessing mirabegron were included. Articles were reviewed and included if mirabegron was used as monotherapy and if the primary outcome analyzed drug efficacy.

Data Synthesis-The efficacy of mirabegron for the treatment of OAB has been demonstrated in the selected five randomized, placebo-controlled trials. The majority of these trials lasted 12 weeks in duration and compared various doses of mirabegron to placebo and/or tolterodine extended release (ER). Primary efficacy outcomes for the trials included mean number of micturitions per 24 hours and mean number of incontinence episodes per 24 hours. Included trials showed statistically significant reductions in both efficacy outcomes for various doses of mirabegron when compared to placebo.

Conclusion-Based on the trials reviewed, mirabegron has been efficacious in reducing mean number of micturitions and incontinence episodes per 24 hours, as well as improved other secondary outcomes like OAB symptoms and quality of life measures. Common adverse drug events seen with mirabegron include: hypertension, nasopharyngitis, urinary tract infections, headache, constipation, upper respiratory tract infection, arthralgia, diarrhea, tachycardia, abdominal pain, and fatigue. Given the efficacy and safety data currently available, mirabegron

Correspondence to: Jamie M. Pitlick, Jamie.pitlick@stlcop. edu.

Disclosure: This manuscript was supported through the Washington University in St. Louis grant ICTS UL1 TR000448. The authors have no potential conflicts of interest. 
represents a reasonable alternative to antimuscarinics for patients with OAB.Future studies are needed to determine the utility of mirabegron for $\mathrm{OAB}$ in a variety of demographics.

\section{Keywords}

beta-3 agonists; new FDA medication; overactive bladder; urge urinary incontinence; urology

\section{Introduction}

Overactive bladder $(\mathrm{OAB})$ is a bothersome urological condition that can affect both men and women. In epidemiological studies the comparative prevalence of OAB increases with age. ${ }^{1-3}$ Based on a cross-sectional survey, frequency, urgency, and urge incontinence affects $13.7 \%, 7.6 \%$, and $4 \%$ of the overall male population, respectively, while it affects $14.6 \%$, $9.7 \%$, and $7.4 \%$ of the overall female population, respectively. ${ }^{1}$ The highest incidence of these symptoms is in both men and women 75 years or older. Medical attention is often not sought by patients with OAB symptoms as patients often attribute the symptoms to an inevitable outcome of aging, a belief there is no effective treatment available, or have a history of previous failure with $\mathrm{OAB}$ medications due to poor efficacy or adverse events. ${ }^{4}$ Because of these factors, only about $20 \%$ of patients with OAB symptoms are treated with pharmacotherapy. ${ }^{3-5}$

Another reason why this condition may be undertreated is that the diagnosis of overactive bladder is very subjective, as the definitions of the hallmark symptoms differ from personto-person and among studies. ${ }^{6}$ The definition of $\mathrm{OAB}$ is the presence of urinary urgency, increased frequency ( 8 or more micturition per waking hours), and nocturia (awaking to urinate one or more times), with or without urinary leakage. ${ }^{6-8}$ In addition, there are a variety of confounders that can affect these definitions such as number of hours slept, fluid intake, and other medical conditions such as diabetes and diuretic use in congestive heart failure. Because these symptoms are subjective, the effect on quality of life typically dictates treatment. One way to identify these subjective symptoms is by using a variety of questionnaires that assess severity of OAB symptoms. ${ }^{6}$

\section{Current Management}

There are several assessments that need to be considered prior to starting pharmacotherapy. A physical exam and laboratory testing need to be performed in order to rule out infection, vaginal atrophy, stool impaction, and diabetes mellitus. Current medications need to be reviewed to determine if symptoms are associated with medications such as diuretics and acetylcholinesterase inhibitors. ${ }^{9}$ Prior to the use of any oral agents for the treatment of $\mathrm{OAB}$, a non-pharmacological approach should be utilized. ${ }^{6}$ Behavioral therapies such as bladder training and pelvic floor exercises can improve symptoms without use of medications. Pharmacotherapy should ultimately be dictated by the subjective symptoms of the patient and can be used in conjunction with these non-pharmacological interventions. ${ }^{6,10}$

Use of Food and Drug Administration (FDA)-approved antimuscarinics dates back to 1975 with the approval of oxybutynin immediate release (IR). ${ }^{11}$ Since then, five new chemical entities with several formulations each have been approved (Figure 1). The United States 
American Urological Association (AUA) guidelines do not recommend one antimuscarinic therapy over another. If an antimuscarinic fails or a patient has an adverse drug reaction to a particular antimuscarinic, another can be tried. ${ }^{6}$

Chapple, et al performed a meta-analysis which evaluated the safety and efficacy of all FDA-approved antimuscarinic medications used to treat OAB. ${ }^{12}$ Across the various studies, there was a significant reduction in incontinence episodes by 0.5 to 1.08 per day from baseline in all antimuscarinics excluding tolterodine IR, which was no different from placebo. Frequency was significantly reduced by 0.54 to 1.3 episodes per day from baseline in all antimuscarinic modalities. Urgency episodes were also significantly reduced by 0.65 to 1.56 episodes per day. Adverse drug reactions (ADRs) typically associated with antimuscarinics include constipation, dry mouth, and blurry vision due to antagonism of the muscarinic (M3) receptor. ${ }^{13}$ In this meta-analysis, patients taking oxybutynin IR were more likely to withdraw from treatment and had a significantly higher incidence of dry mouth compared to other antimuscarinics. ${ }^{12}$ Additionally, solifenacin and darifenacin were more likely to cause constipation, and solifenacin was more likely to cause blurred vision compared to other antimuscarinics. There are also concerns for using antimuscarinics in the elderly due to their potential for cognitive dysfunction. ${ }^{14}$ Contraindications also exist for using antimuscarinics in patients with acute urinary retention.

\section{Beta-3 agonists for OAB}

The mechanism of micturition is a complicated process involving both voluntary and involuntary actions in the urinary tract through innervation of the parasympathetic, sympathetic, and somatic nerve pathways. Additionally, there are several neurohormonal pathways which control the filling and voiding phases. As the bladder fills with urine, it normally is able to maintain a low intravesical pressure via sympathetic nerve stimulation despite the increasing volume. ${ }^{15}$ Acetylcholine, which is normally released during the voiding phase, binds to the muscarinic receptors on the detrusor. Of the five known subtypes of muscarinic receptors, M3 receptors are responsible for causing involuntary contractions during normal micturition. ${ }^{13,16}$ When the bladder is full acetylcholine stimulates involuntary bladder contractions, which reduces sympathetic beta-3 activity. ${ }^{17}$ Until recently, antimuscarinics, were the only medications approved for the treatment of OAB. ${ }^{13,16}$

In 2012, the FDA approved the first non-antimuscarinic oral medication, mirabegron, to treat patients with $\mathrm{OAB}$ symptoms. Although mirabegron is a relatively new medication, the pathway involved in its mechanism was discovered approximately 20 years ago; however, the process of approving this medication was delayed due to potential cardiac side effects. ${ }^{18-19}$ Mirabegron works via the sympathetic nerve pathway and stimulates beta-3 receptors, causing smooth muscle relaxation in the bladder. ${ }^{18,20}$ The use of a beta-3 agonist is specific to the bladder as $97 \%$ of the beta adrenergic receptor subtypes are the beta- 3 subtype. ${ }^{17}$ As mirabegron does not cause antagonism of M3 receptors, it is postulated that there is a lower risk for urinary retention compared to antimuscarinic agents. ${ }^{17,20}$ 


\section{Dosing and Administration}

The initial dose of Mirabegron (Myrbetriq ${ }^{\circledR}$ ) is $25 \mathrm{mg}$ by mouth taken at approximately the same time every day, swallowed whole, with or without food. After eight weeks, the dose can be titrated to $50 \mathrm{mg}$ by mouth daily based on an individual's response. It is not recommended to exceed $25 \mathrm{mg}$ by mouth daily in patients with severe renal disease (estimated creatinine clearance $<30 \mathrm{~mL} / \mathrm{min}$ ) or moderate hepatic impairment (Child-Pugh Class B). In addition, it should be avoided altogether in patients with end stage renal disease or severe hepatic impairment (Child-Pugh Class C). Mirabegron is a moderate cytochrome $\mathrm{P}$ (CYP) 450 inhibitor of 2D6 and should be used in caution with 2D6 substrates (i.e. metoprolol, desipramine, flecainide, and propafenone). ${ }^{21}$

\section{Clinical Trials}

A MEDLINE (PubMed) search was performed for studies prior to December $31^{\text {st }}, 2013$. For this review, the terms "mirabegron" and "randomized controlled trial" were used to identify publications. Only published, randomized, controlled trials (RCTs) with OAB efficacy endpoints as the primary outcome were included. Our search resulted in 10 trials, of which three met the criteria for inclusion. Other search strategies (i.e. reference lists of primary papers searched) identified two additional relevant studies. The five trials included are described in detail in Table 1 and results are listed in Table 2. The patient population included in these trials consisted of $>65 \%$ females and $>85 \%$ Caucasians. The average age ranged from 55 to 61 years of age, with $>80 \%$ of patients under the age of 75 . Of the trials that reported the following criteria, $40-50 \%$ of patients had taken a prior OAB medication and patients averaged approximately 11 micturition per 24 hours at baseline.

There are two Phase II trials performed by Chapple, et al: the BLOSSOM trial and the DRAGON trial. The BLOSSOM trial showed a statistically significant reduction in the mean number of micturition per 24 hours when compared to placebo for mirabegron 100mg BID ( $-1.02,95 \%$ Confidence Interval (CI), -1.67 to -0.36$)$ and mirabegron 150mg BID $(-1.03,95 \% \mathrm{CI},-1.69$ to -0.372$)$; however, there was no statistically significant improvement with tolterodine ER $4 \mathrm{mg}(-0.4,95 \% \mathrm{CI},-1.06$ to 0.26$) .^{22}$

In the DRAGON trial there was a statistically significant reduction in the mean number of micturition episodes per 24 hours compared to placebo for mirabegron 50mg $(-0.64,95 \%$ $\mathrm{CI},-1.19$ to -0.1$)$, mirabegron $100 \mathrm{mg}(-0.68,95 \% \mathrm{CI},-1.22$ to -0.13$)$, and mirabegron 200mg $(-0.8,95 \% \mathrm{CI},-1.34$ to -0.25$)$; however there was not a significant reduction with mirabegron $25 \mathrm{mg}(-0.45,95 \% \mathrm{CI},-0.99$ to 0.1$)$ or tolterodine ER $4 \mathrm{mg}(-0.52,95 \% \mathrm{CI}$, -1.18 to 0.15$).^{23}$

In the study by Nitti, et al there were significant improvements from baseline in incontinence episodes per 24 hours for mirabegron 50mg ( $-1.47,95 \%$ CI, -1.69 to -1.255$)$ and mirabegron 100mg $(-1.63,95 \% \mathrm{CI}-1.86$ to -1.4$)$. Additionally, there were significant reductions in the number of micturition per 24 hours from baseline for mirabegron $50 \mathrm{mg}$ $(-1.66,95 \% \mathrm{CI}-1.92$ to -1.4$)$ and mirabegron $100 \mathrm{mg}(-1.75,95 \% \mathrm{CI}-2.01$ to -1.48$) .{ }^{24}$ 
In the evaluation by Khullar, et al there were significant improvements from baseline in incontinence episodes per 24 hours for mirabegron 50mg ( $-0.41,95 \%$ CI, -0.72 to -0.09$)$ and mirabegron $100 \mathrm{mg}(-0.29,95 \% \mathrm{CI}-0.61$ to $0.03 ; \mathrm{p}=0.01$ after multiplice adjustments); however, this was not seen in tolterodine ER $4 \mathrm{mg}(-0.1,95 \% \mathrm{CI}-0.42$ to 0.21$)$. Additionally, there were statistically significant reductions in the number of micturition per 24 hours for mirabegron 50mg ( $-0.6,95 \%$ CI -0.9 to -0.29$)$ and mirabegron $100 \mathrm{mg}(-0.44$, $95 \%$ CI -0.74 to -0.13$)$; however, there was no difference when tolterodine ER $4 \mathrm{mg}(-0.25$, $95 \%$ CI -0.55 to 0.06 ) was compared to placebo. ${ }^{25}$

In a study by Herschorn, et al mirabegron $25 \mathrm{mg}(-0.40,95 \%$ CI -0.74 to -0.06$)$ and $50 \mathrm{mg}$ $(-0.42,95 \%$ CI -0.76 to -0.08$)$ showed a statistically significant decrease in the mean number of incontinence episodes per 24 hours when compared to placebo. There was also a statistically significant decrease in the mean number of micturition per 24 hours for both mirabegron $25 \mathrm{mg}(-0.47,95 \% \mathrm{CI}-0.82$ to -0.13$)$ and mirabegron $50 \mathrm{mg}(-0.42,95 \% \mathrm{CI}$ -0.76 to -0.08$)$ when compared to placebo. ${ }^{26}$

An additional study evaluating mirabegron was not included above as the primary outcome was safety. Chapple, et al performed a randomized, double-blind, active-controlled phase III trial (TAURUS trial). ${ }^{27}$ Patients $\geq 18$ years of age with OAB symptoms for $\geq 3$ months were enrolled in a 2 week single-blind, placebo run-in. Patients were randomized ( $n=2452)$ 1:1:1 to mirabegron 50mg ( $\mathrm{n}=815)$, mirabegron $100 \mathrm{mg}(\mathrm{n}=824)$, or tolterodine ER $4 \mathrm{mg}(\mathrm{n}=813)$ once daily for 12 months. The primary variable was the incidence and severity of treatment emergent adverse events (TEAEs) starting from the first double-blind study drug intake until 30 days after the last study drug dose. Efficacy end points consisted of the change in key $\mathrm{OAB}$ symptoms recorded in the 3-day micturition diary from baseline to months $1,3,6$, and 12. There was no statistically significant difference between mirabegron and tolterodine in the efficacy assessment.

A recent pooled analysis incorporating data from three of the previously discussed phase III studies evaluated the efficacy of mirabegron $50 \mathrm{mg}(\mathrm{n}=1324)$ and $100 \mathrm{mg}(\mathrm{n}=890)$ once daily. ${ }^{28}$ The co-primary outcomes included change from baseline to final visit in the mean number of incontinence episodes per 24 hours and mean number of micturition per 24 hours. This pooled analysis found a statistically significant decrease for both co-primary outcomes for both doses of mirabegron. There was a reduction in the mean number of incontinence episodes per 24 hours compared to placebo for mirabegron $50 \mathrm{mg}(-0.40,95 \% \mathrm{CI}-0.58$ to $-0.21)$ and mirabegron $100 \mathrm{mg}(-0.41,95 \% \mathrm{CI}-0.62$ to -0.19$)$ and in the change in the mean number of micturition per 24 hours compared to placebo for mirabegron $50 \mathrm{mg}(-0.55$, $95 \% \mathrm{CI}-0.75$ to -0.36$)$ and mirabegron $100 \mathrm{mg}(-0.54,95 \% \mathrm{CI}-0.77$ to -0.31$)$.

\section{Secondary Efficacy Outcomes}

The above five trials assessed mirabegron using primary or co-primary efficacy end points.

However, other secondary end points were evaluated using objective data endpoints such as mean volume voided per micturition; mean number of urinary incontinence and urgency episodes per 24 hours; severity of urgency; and nocturia, along with subjective improvements in $\mathrm{OAB}$ symptoms and quality of life measurements using questionnaires (Table 2). These assessments include the OAB Questionnaire (OAB-q), the Patient 
Perception of Bladder Condition (PPBC), and the Treatment Satisfaction-Visual Analog Scale (TS-VAS). The OAB-q involves multiple questions assessing the patient's symptom bother, coping, concern, sleep, and social aspects related to overactive bladder. The PPBC asks patients to rate their perceived bladder condition on a scale from 1 (indicating no problems) to 6 (indicating severe problems), and the TS-VAS is a measurement of current health status.

\section{Limitations}

While all of the trials demonstrated improvements in $\mathrm{OAB}$ symptoms and patient-reported outcomes, several limitations exist in these studies. Many of the trials included patients who had already participated in earlier phase studies of mirabegron, and approximately $80 \%$ of the participants in TAURUS had completed a recent mirabegron trial. ${ }^{27}$ While the previously discussed studies were all blinded, prior participant exposure to the study drug may confound the results.

Another limitation is that differing doses of mirabegron were used in each of the trials, which makes a consistent assessment of all studies difficult. However, all doses studied did show similar improvements in OAB symptoms and patient-reported outcomes. In addition, many of the data in these trials are patient-reported via micturition diaries and questionnaires which have not been standardized. This subjective data in the trials could be considered a confounder; however, this method of utilizing subjective data is consistent with previous studies assessing $\mathrm{OAB}$ medications.

Patients in these trials may not be representative of all patients affected by OAB. The majority of patients in each study were female with an age range of 55-61 years old, which does not encompass older males who suffer from $\mathrm{OAB}$ and may limit the external validity of these studies. For example, most of the study populations were comprised of $>65 \%$ females, with $>80 \%$ of the population younger than 75 years old..$^{2-27}$ The durations of the trials were also short and may not allow for a full assessment of adverse effects and maintenance of efficacy throughout a prolonged period of time. The TAURUS trial was 12 months long and it concluded that the safety and efficacy profile of mirabegron identified in shorter trials was maintained throughout its trial period, with no new relevant safety concerns that could be attributed to the drug and no decrease in efficacy. ${ }^{27}$

An overall limitation of these trials is that they have not directly compared mirabegron to the current standard of therapy. While tolterodine ER was included in some studies, there was not a direct statistical comparison of non-inferiority or superiority made between mirabegron and tolterodine ER as these trials only demonstrated efficacy versus placebo or compared to baseline OAB symptoms. ${ }^{22-27}$

\section{Adverse Effects}

\section{Prevalence of Adverse Effects}

Overall, the trials discussed above demonstrated the tolerability of mirabegron and no lifethreatening adverse events were noted in these particular studies. The main adverse drug 
reactions from mirabegron in these trials were hypertension, dry mouth, constipation, and headache.

TEAEs were consistent for mirabegron throughout the 5 studies and the TAURUS study. The BLOSSOM trial had similar rates in the mirabegron groups $-18.5 \%-24.6 \%$ compared to tolterodine ER $4 \mathrm{mg}-26.6 \%(\mathrm{n}=17){ }^{22}$ The DRAGON trial had lower TEAEs in the tolterodine cohort $-15.3 \%(\mathrm{n}=13)$ compared to the mirabegron combination group $-20.1 \%$ $22.5 \%{ }^{23}$ The TEAEs were similar across the treatment groups in the SCORPIO trial for mirabegron 50mg/day, $100 \mathrm{mg} /$ day, and tolterodine ER $4 \mathrm{mg} /$ day at $42.8 \%(\mathrm{n}=211), 40.1 \%$ $(\mathrm{n}=199), 46.7 \%(\mathrm{n}=231)$, respectively. ${ }^{25}$ The ARIES trial did not report total TEAEs for each treatment group. ${ }^{24}$ Additionally, the TAURUS trial, an evaluation of 12 month use of medications, established that TEASs occurred at a similar rate between mirabegron $50 \mathrm{mg}$, $100 \mathrm{mg}$, and tolterodine ER 4mg, with total prevalence of adverse effects at 59.7\% ( $\mathrm{n}=485)$ for mirabegron 50mg, 61.3\% $(\mathrm{n}=503)$ for mirabegron $100 \mathrm{mg}$, and $62.6 \%(\mathrm{n}=508)$ for tolterodine ER 4mg/day, respectively. Discontinuation rates were similar in active-treatment groups within each study. ${ }^{23,25,27}$

\section{Increases in Heart Rate/Blood Pressure}

There appears to be a dose dependent increase in heart rate and blood pressure with the use of mirabegron. There was no significant increase in heart rate in mirabegron $25 \mathrm{mg} /$ day in either the morning or afternoon, $0.34 \mathrm{bpm}$ and $0.49 \mathrm{bpm}$, respectively $(p>0.05),{ }^{23}$ or in mirabegron $50 \mathrm{mg} /$ day in the morning or afternoon, $0.8-1.64 \mathrm{bpm}$ and $0.7-1.12 \mathrm{bpm}$, respectively $(p>0.05) .{ }^{23,25}$ In the BLOSSOM trial, subjects taking mirabegron 150mg BID had a $5 \mathrm{bpm}$ increase compared to no change in mirabegron 100mg BID and tolterodine ER $4 \mathrm{mg} /$ day. ${ }^{22}$ In trials of higher doses there were significant increases in heart rate. There was an increase of 1.6-2.5 bpm in the morning and 2.0-2.71 bpm in the afternoon in mirabegron $100 \mathrm{mg} /$ day $(p<0.05){ }^{23,25}$ There was also a $4.63-4.66 \mathrm{bpm}$ increase in the mirabegron $200 \mathrm{mg} /$ day group $(p<0.001)$; however, there were no reported cardiac adverse effects. ${ }^{23}$ Changes in heart rate were not reported in the ARIES trial. ${ }^{24}$

When evaluating the impact on blood pressure, the TAURUS trial showed minimal changes from baseline for each group. The systolic and diastolic blood pressure (SBP/DBP) changes for mirabegron $50 \mathrm{mg} /$ day were $+0.2 /-0.3 \mathrm{mmHg},+0.4 /+0.4 \mathrm{mmHg}$ for mirabegron $100 \mathrm{mg}$ / day, and $-0.5 /+0.1 \mathrm{mmHg}$ for tolterodine ER $4 \mathrm{mg} /$ day. ${ }^{27}$ This small increase in blood pressure would likely not be considered clinically significant by most practitioners. The incidence of blood pressure increases in the other trials described was similar between the groups (4.9\% to $6.1 \%) .{ }^{24-25}$ Caution still should be taken as it was reported that 5-6\% of patients taking mirabegron have experienced an increase in blood pressure of $15 / 10 \mathrm{mmHg}$ or more. ${ }^{21}$ Overall, the approved doses of mirabegron $25 \mathrm{mg} / \mathrm{day}$ and $50 \mathrm{mg} /$ day have yet to yield significant increases in heart rate or blood pressure; however, it would be suggested to monitor closely.

\section{Anticholinergic Adverse Effects}

One potential difference between mirabegron and antimuscarinics are anticholinergic side effects, including dry mouth and constipation. The SCORPIO trial and TAURUS trial did 
see an increased risk for dry mouth in the tolterodine group (8.6-10.1\%) compared to mirabegron $50 \mathrm{mg}$ /day and $100 \mathrm{mg} /$ day $(2.3-2.8 \%) .{ }^{25-27}$ However, rates of dry mouth were similar in the DRAGON and BLOSSOM trials between the tolterodine groups $(3.5-4.7 \%)$ and the mirabegron groups $(0-6.2 \%) \cdot{ }^{23-23}$ Across these studies, there were similar rates of constipation in the tolterodine ER groups $(1.2-2.7 \%)$ and the mirabegron groups $(1.2-$ $3.0 \%)^{22-23,25,27}$

\section{Other Adverse Effects}

Overall there were low incidences $(<1 \%)$ of elevated post-void residual volumes in any of the treatment groups. ${ }^{22-23,25}$ Incidence of headache was similar in tolterodine ER groups and mirabegron groups $(1.2-6.3 \%$ vs. $1.8-4.6 \%)$, respectively. ${ }^{22-24,25}$

\section{Drug Interactions}

Mirabegron is a minor substrate of CYP2D6, CYP3A4, and P-glycoprotein. It is a moderate inhibitor of CYP2D6 and a weak inhibitor of CYP3A4. While no dose adjustments are recommended during co-administration with the majority of CYP2D6 substrates, appropriate monitoring should occur since mirabegron can significantly increase the concentrations of these agents. ${ }^{21} \mathrm{~A}$ study with metoprolol and mirabegron showed that the combination of multiple doses of mirabegron $160 \mathrm{mg} /$ day and a single dose of metoprolol $100 \mathrm{mg} /$ day showed an increase in the area under the curve (AUC) of metoprolol by 3.29 fold and mean increase in half-life from 2.96 hours to 4.11 hours. ${ }^{29}$ Similar to metoprolol, there was a 3.41 fold increase in AUC of desipramine and mean increase in half-life from 19.5 hours to 35.8 hours after a $50 \mathrm{mg}$ single dose of desipramine was administered to patients having taken multiple doses of mirabegron $100 \mathrm{mg} / \mathrm{day} .{ }^{29}$ Monitoring should also be employed with CYP2D6 substrates with narrow therapeutic indices such as thioridazine, flecainide, and propafenone. A dose adjustment is recommended when initiating digoxin with mirabegron. The lowest digoxin dose should be used initially and serum digoxin concentrations should be utilized to titrate the digoxin to the therapeutic range. Although the combination of warfarin and mirabegron requires further investigation, multiples doses of warfarin with mirabegron 100mg have resulted in an increased AUC and Cmax of warfarin with a potential increase in INR. ${ }^{21}$ Overall, mirabegron does not appear to have any significant drug interactions in patients who are regular metabolizers of CYP2D6. However, diligence is necessary especially in elderly patients taking multiple medications that may be metabolized by enzymes involved with mirabegron.

Anticholinergic agents may increase the effects of mirabegron based on its side effect profile. Although no dose adjustment is recommended, mirabegron should be used with caution with antimuscarinic drugs such as solifenacin for the treatment of OAB due to the risk of urinary retention. ${ }^{30}$ In terms of food interactions, low-fat meals have been shown to decrease the AUC of mirabegron more than high-fat meals. ${ }^{21}$ One randomized crossover study by Lee and colleagues showed a decrease in mirabegron plasma exposure that was dependent on meal composition but not dose, resulting in a greater decrease in mirabegron exposure after a low-fat versus high-fat meal. When mirabegron 50 or 100mg was combined with a high-fat meal, the Cmax was decreased by $39-45 \%$ and the AUC was decreased by $17-18 \%$. When these doses were combined with a low-fat meal, the Cmax was decreased by 
$64-75 \%$ and the AUC was decreased by $47-51 \%$. In both groups, the $90 \%$ CI fell below the limits for bioequivalence of $80-125 \%$, which indicates an effect of food on mirabegron. However, all other phase 3 mirabegron trials, in which mirabegron was administered irrespective of food intake, demonstrated similar efficacy and tolerability. Overall, safety and efficacy were not clinically affected by food and mirabegron may be administered without regard to food. ${ }^{31}$

\section{Future Directions/Place in Therapy}

Recent evidence suggests mirabegron as a viable alternative to antimuscarinic therapy. First, antimuscarinic therapy in older adults can contribute to anticholinergic side effects such as constipation, dry eyes, and confusion. Therefore, having a non-antimuscarinic alternative may be useful for treating $\mathrm{OAB}$ without contributing to these symptoms. Although most studies looked at non-elderly adults, a published abstract of pooled results from subjects 65 or older compared to subjects less than 65 years of age suggest similar efficacy between both groups. ${ }^{32}$ Safety was not assessed and future studies are needed to determine safety endpoints in the older adult population. Second, there are no published studies assessing combination antimuscarinic therapy with beta- 3 agonists; however, there are active studies assessing this question.

Currently, the AUA Guidelines (2012) on OAB indicate that the use of a beta-3 agonist shows promise, but do not include specific recommendations for mirabegron in the treatment algorithms. ${ }^{6}$ It can be postulated that mirabegron may be recommended as second line treatment after antimuscarinic failure due to poor efficacy or ADRs. As it has been recently approved, consideration of cost and insurance coverage may prevent it from being routinely used as a first-line therapy for OAB.

\section{Conclusion}

To date, mirabegron has demonstrated data in both safety and efficacy for patients with OAB. In 2012, mirabegron was approved by the FDA at the dose of $25 \mathrm{mg}$ by mouth daily, which can be titrated to $50 \mathrm{mg}$ by mouth daily. The most common adverse effects when used for this indication include hypertension, constipation, and headache. This medication has shown improvement in symptoms based on reductions in frequency, urgency, and incontinence episodes, along with other subjective OAB tests. It is a new option for patients with $\mathrm{OAB}$ which avoids potential anticholinergic adverse effects. Although some literature suggests it may be safe and effective, future studies are needed to determine its utility for $\mathrm{OAB}$ in a variety of demographics.

\section{Abbreviations}

$\begin{array}{ll}\text { ADRs } & \text { Adverse drug reactions } \\ \text { AUA } & \text { American Urological Association } \\ \text { AUC } & \text { Area under the curve } \\ \text { BID } & \text { Twice daily }\end{array}$




$\begin{array}{ll}\text { cAMP } & \text { cyclic adenosine monophosphate } \\ \text { CI } & \text { Confidence interval } \\ \text { CYP } & \text { Cytochrome P } \\ \text { DBP } & \text { Diastolic blood pressure } \\ \text { ER } & \text { Extended release } \\ \text { FDA } & \text { Food and Drug Administration } \\ \text { IR } & \text { Immediate release } \\ \text { M3 } & \text { Muscarinic 3 receptor } \\ \text { OAB } & \text { Overactive bladder } \\ \text { OAB-Q } & \text { Overactive Bladder Questionnaire } \\ \text { PPBC } & \text { Patient perception of bladder condition } \\ \text { RCT } & \text { Randomized controlled trial } \\ \text { SBP } & \text { Systolic blood pressure } \\ \text { TEAs } & \text { Treatment emergent adverse events } \\ \text { TS-VAS } & \text { Treatment Satisfaction-Visual Analog Scale }\end{array}$

\section{References}

1. Milsom I, Stewart W, Thuroff JW. The prevalence of overactive bladder. Am J Manag Care. 2000; 6(11 Suppl):S565-73. [PubMed: 11183899]

2. Tubaro A. Defining overactive bladder: epidemiology and burden of disease. Urology. 2004; 64(Suppl 6):2-6. [PubMed: 15621220]

3. Gomelsky A. Urinary incontinence in the elderly female. Ann Longterm Care. 2009; 17(10):41-5.

4. Milsom I, Abrams P, Cardozo L, et al. How widespread are the symptoms of overactive bladder and how are they managed? A population-based prevalence study. BJU Int. 2001; 87:760-6. [PubMed: 11412210]

5. Nitti V, Taneja S. Overactive bladder: achieving a differential diagnosis from other lower urinary tract conditions. Int J ClinPrac. 2005; 59(7):825-30.

6. American Urological Guidelines. [Accessed January 24, 2013] Diagnosis and treatment of overactive bladder (non-neurogenic) in adults. 2012. Available at http://www.auanet.org/content/ media/OAB_guideline.pdf

7. Haylen BT, de Ridder D, Freeman RM, et al. An International Urogynecological Association/ International Continence Society joint report on the terminology for female pelvic floor dysfunction. IntUrogynecol J. 2010; 21:5-26.

8. Abrams P, Cardozo L, Fall M, et al. The standardization of terminology of lower urinary tract function. NeurourolUrodyn. 2002; 21:167-78.

9. Lavelle JP, Karram M, Chu FM, et al. Management of incontinence for family practice physicians. Am J Med. 2006; 119(3A):37S-40S.

10. Wyman JF, Burgio KL, Newman DK. Practical aspects of lifestyle modifications and behavioural interventions in the treatment of overactive bladder and urgency incontinence. Int J ClinPract. 2009; 63(8):1177-91.

11. Marinkovic SP, Rovner ES, Moldwin RM, et al. The management of overactive bladder syndrome. BMJ. 2012; 344:38-44. 
12. Chapple CR, Khullar V, Gabriel Z, et al. The effects of antimuscarinic treatments in overactive bladder: an update of a systematic review and meta-analysis. Eur Urol. 2008; 54:543-62. [PubMed: 18599186]

13. Abrams P, Andersson KE. Muscarinic receptor antagonists for overactive bladder. BJU Int. 2007; 100:987-1006. [PubMed: 17922784]

14. Wagg A. Treating overactive bladder in the elderly. Can Urol Assoc J. 2011; 5(5Suppl2):S149-51. [PubMed: 21989530]

15. Fowler CJ. Integrated control of lower urinary tract - clinical perspective. Brit J Pharmacol. 2006; 147:S14-24. [PubMed: 16465178]

16. Mansfield KJ, Chandran JJ, Vaux KJ. Comparison of receptor binding characteristics of commonly used muscarinic antagonists in human bladder detrusor and mucosa. J Pharmacol Exp Ther. 2009; 328(3):893-9. [PubMed: 19029429]

17. Igawa Y, Aizawa N, Homma Y. Beta3-adrenoceptor agonists: possible role in the treatment of overactive bladder. Korean J Urol. 2010; 51:811-8. [PubMed: 21221199]

18. Andersson KE, Hedlund P. Pharmacologic perspective on the physiology of the lower urinary tract. Urology. 2002; 605(Suppl 1):13-21. [PubMed: 12493344]

19. Andersson KE. Prospective pharmacologic therapies for the overactive bladder. Ther Adv Urol. 2009; 1(2):71-83. [PubMed: 21789056]

20. Ouslander J. Management of overactive bladder. N Engl J Med. 2004; 350(8):785-99.

21. Myrbetriq (mirabegron) [prescribing information]. AstellasPharma US, Inc; Northbrook, IL: Jun. 2012

22. Chapple CR, Amarenco G, Lopez MA, et al. A proof-of-concept study: mirabegron, a new therapy for overactive bladder (BLOSSOM trial). Neurourol Urodynam. 2013; 32(8):1116-22.

23. Chapple CR, Dvorak V, Radziszewski P, et al. A phase II dose-ranging study of mirabegron in patients with overactive bladder (DRAGON trial). Int Urogynecol. 2013; 24(9):1447-58.

24. Nitti VW, Auerbach S, Martin N, et al. Results of a randomized phase III trial of mirabegron in patients with overactive bladder (ARIES trial). J Urol. 2013; 189(4):1388-95. [PubMed: 23079373]

25. Khullar V, Amarenco G, Angulo JC, et al. Efficacy and tolerability of mirabegron, a $\beta(3)$ adrenoceptor agonist, in patients with overactive bladders: results from a randomized EuropeanAustralian phase 3 trial (SCORPIO trial). Eur Urol. 2013; 63(2):283-95. [PubMed: 23182126]

26. Herschorn S, Barkin J, Castro-Diaz D, et al. A phase III, randomized, double-blind, parallel-group, placebo-controlled, multicenter study to assess the efficacy and safety of the beta-3 adrenoceptor agonist, mirabegron, in patients with symptoms of overactive bladder. Urology. 2013; 82(2):31320. [PubMed: 23769122]

27. Chapple C, Kaplan S, Mitcheson H, et al. Randomized, double-blind, active-controlled phase III study to assess 12 -month safety and efficacy of mirabegron, a $\beta_{3}$-adrenoceptor agonist, in overactive bladder (TAURUS trial). EurUrol. 2013; 63:296-305.

28. Nitti VW, Khullar V, van Kerrebroeck P, et al. Mirabegron for the treatment of overactive bladder: a prespecified pooled efficacy analysis and pooled safety analysis of three randomized, doubleblind, placebo-controlled, phase III studies. Int J Clin Pract. 2013; 67(7):619-32. [PubMed: 23692526]

29. Krauwinkel W, Dickinson J, Schaddelee M, et al. The effect of mirabegron, a potent and selective beta3-adrenoceptor agonist, on the pharmacokinetics of CYP2D6 substrates desipramine and metoprolol. Eur J Drug Metab Pharmacokinet. 2014; 39(1):43-52. [PubMed: 23728524]

30. Tyagi P, Tyagi V, Chancellor M. Mirabegron: a safety review. Expert Opin Drug Saf. 2011; 10(2): 287-94. [PubMed: 21142693]

31. Lee J, Zhang W, Moy S, et al. Effects of food intake on the pharmacokinetic properties of mirabegron oral controlled absorption system: a single-dose, randomized, crossover study in healthy adults. ClinTher. 2013; 35(3):333-41.

32. Khullar, V.; Cambronero, J.; Angulo, J., et al. Age-related efficacy of the selective b3adrenoceptor agonist mirabegron for the treatment of overactive bladder: pooled analysis of three prospective, randomized phase III studies in patients aged $\geq 65$ years; International Continence Society. 2013. p. Abstract 331Accessed at: http://www.ics.org/Abstracts/Publish/134/000331.pdf 


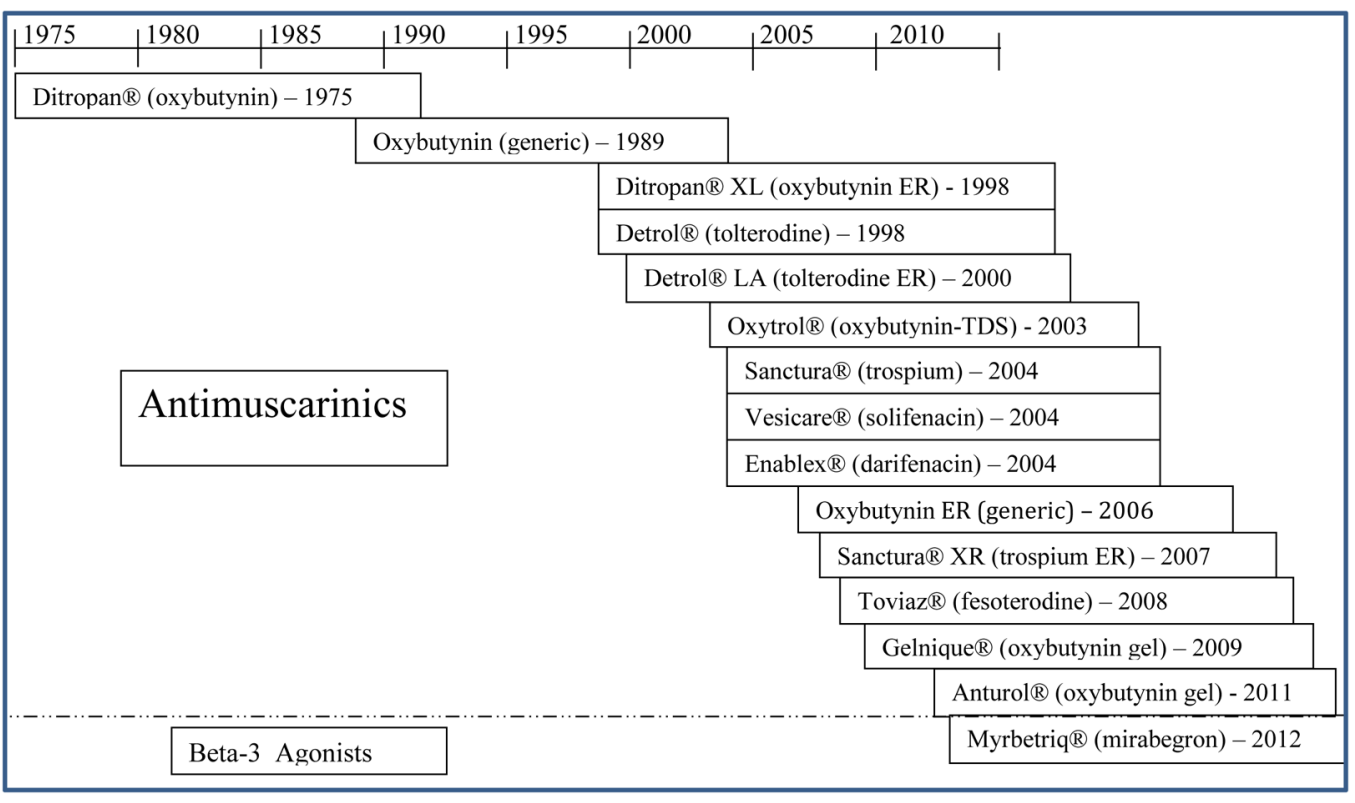

Figure 1. History of OAB Medications FDA Approvals

Source: http://www.accessdata.fda.gov/scripts/cder/drugsatfda/ 


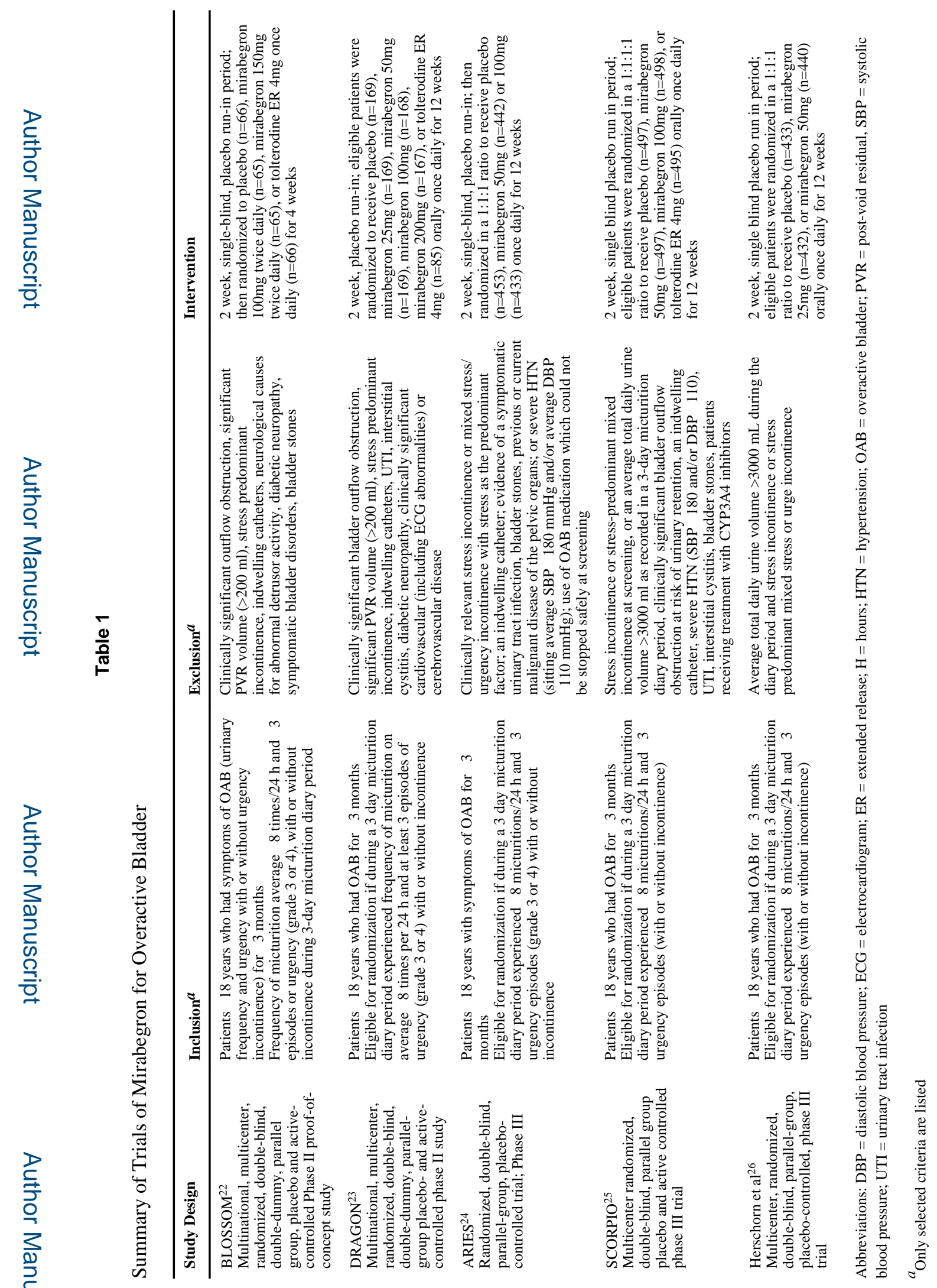

Consult Pharm. Author manuscript; available in PMC 2015 December 01. 


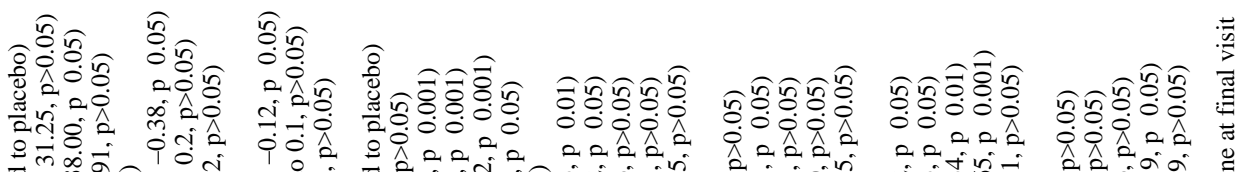

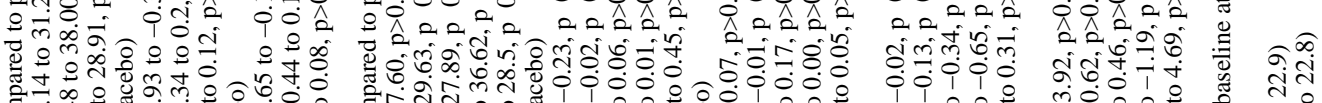

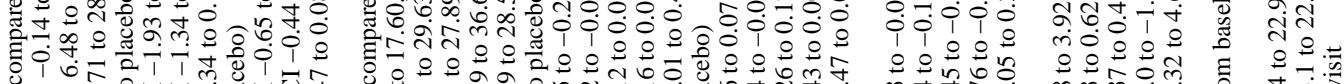

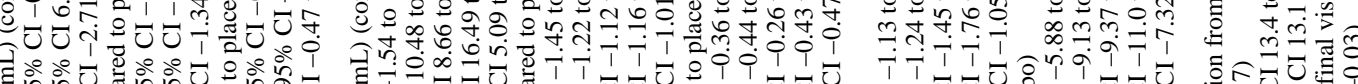

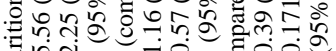

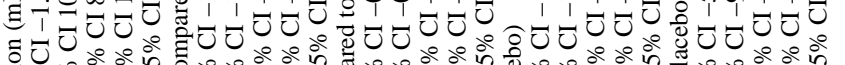

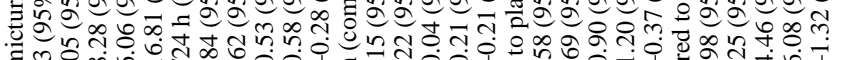

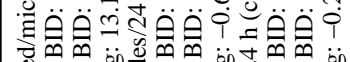

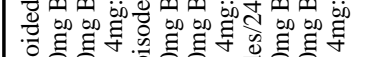

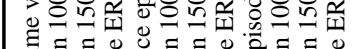

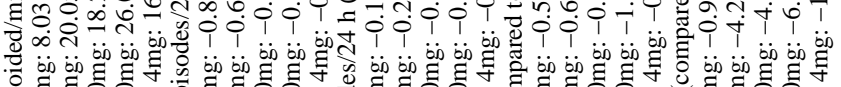

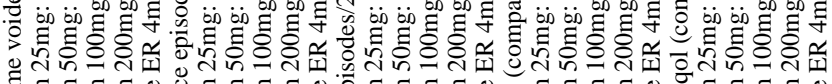

\section{家}

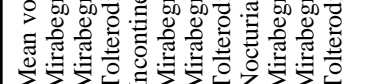

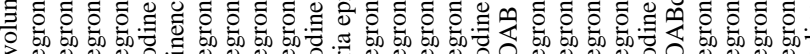

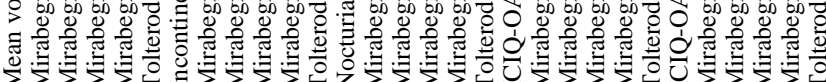

$=0$

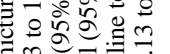

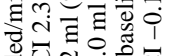

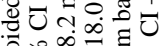

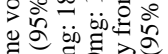

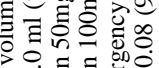

웅ㅎㅇ

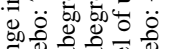
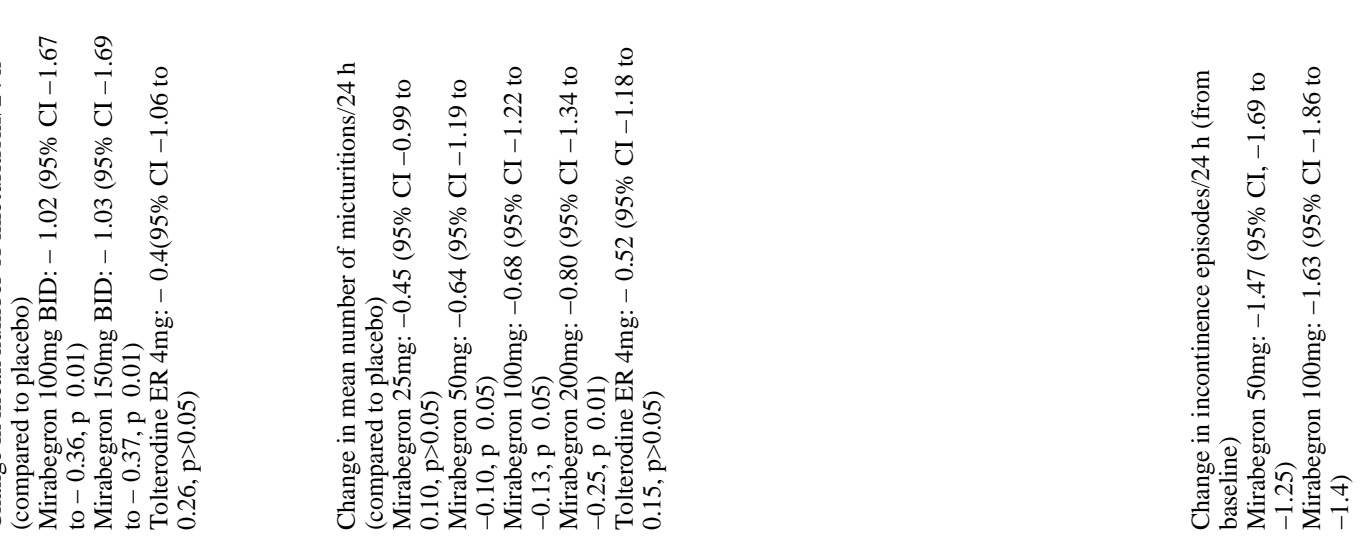

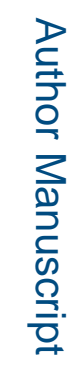

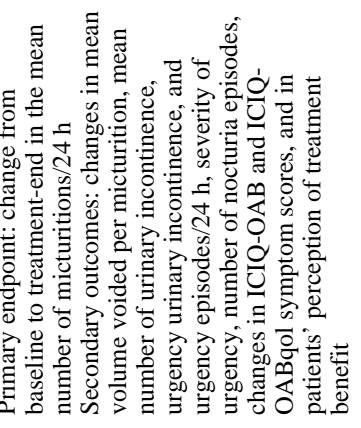

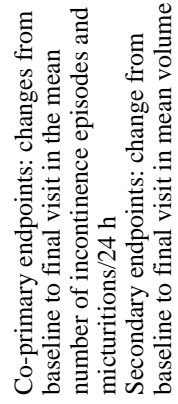

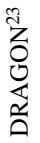

雚 


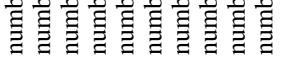

仓ें

on

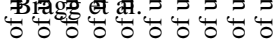

Page 15

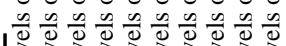

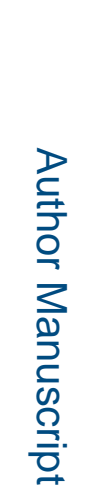

thtm

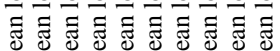

$-{ }^{-1}$

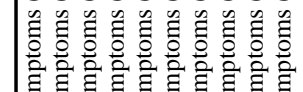

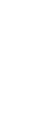

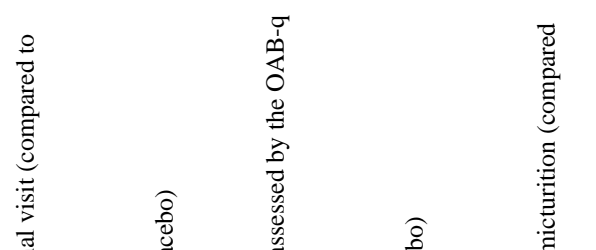

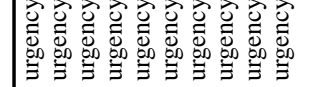

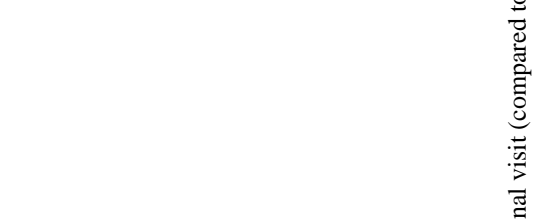

$\vec{z} \vec{z} \vec{t}$

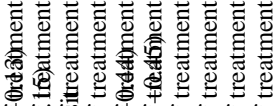

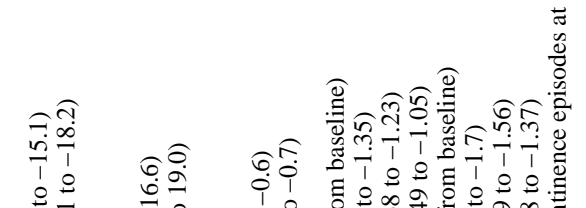

6.

$\operatorname{aic}_{0}^{\infty} \hat{i}$

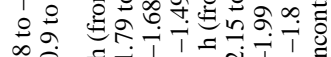

अ,i

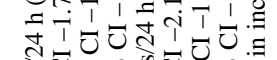

s。o

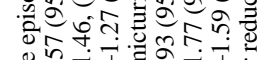

is

$\begin{array}{lll}0 & 0 \\ 0 & 0 & 0 \\ 0 & 0 & 0\end{array}$

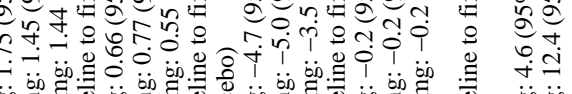

ส두유:

IIIII

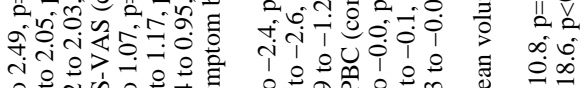

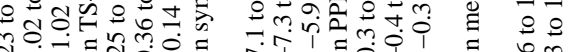

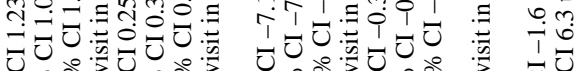

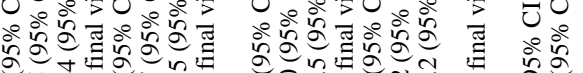

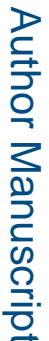

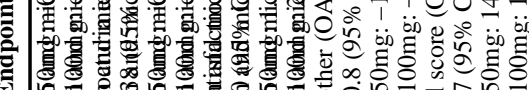

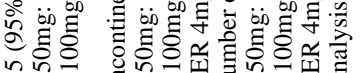

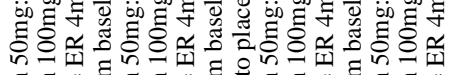

हूँ

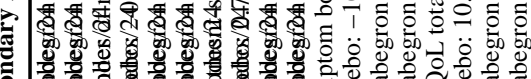

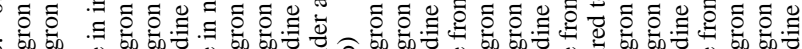

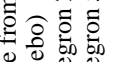

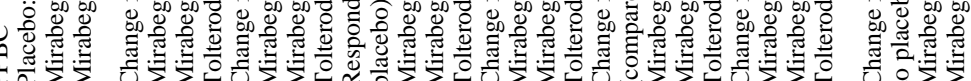

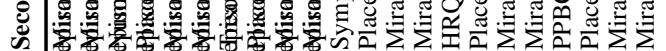

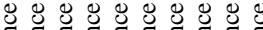

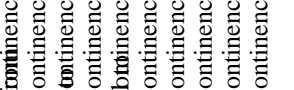

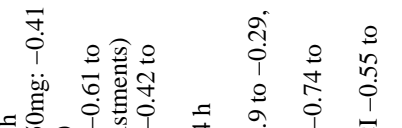

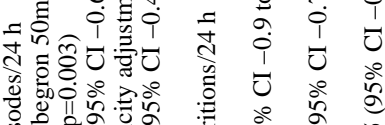

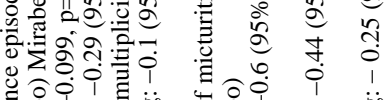

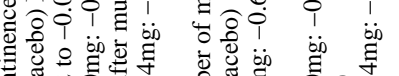

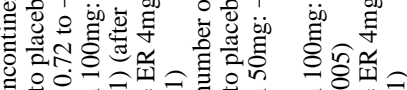

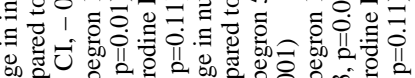

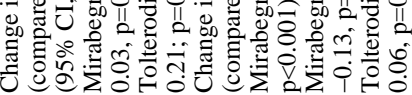

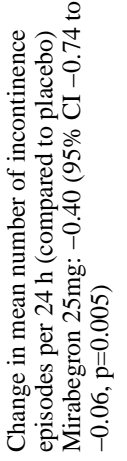

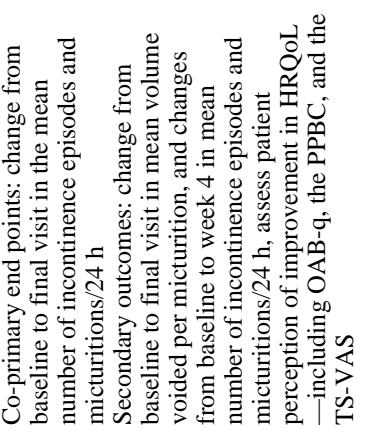

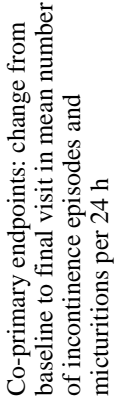

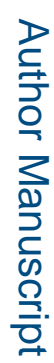

일

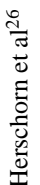

Consult Pharm. Author manuscript; available in PMC 2015 December 01. 


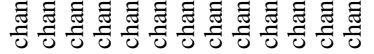

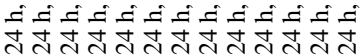

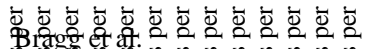

Page 16

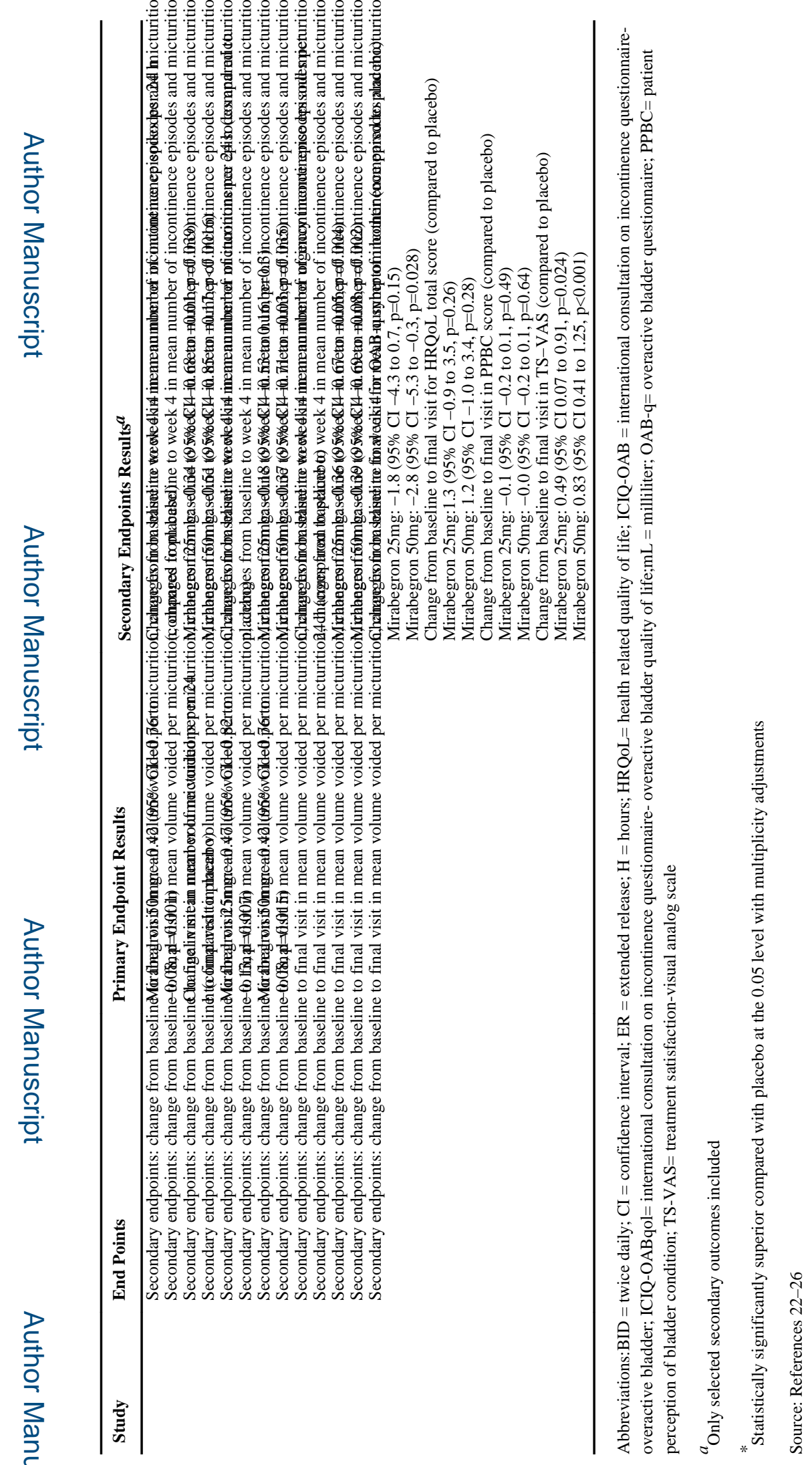

Consult Pharm. Author manuscript; available in PMC 2015 December 01. 